\title{
Design of English Vocabulary Mobile Apps Using Gamification: An Indonesian Case Study for Kindergarten
}

\author{
https://doi.org/10.3991/ijep.v10i1.11551 \\ Gabriel Indra Widi Tamtama, Paulus Suryanto, Suyoto ${ }^{(\varpi)}$ \\ Universitas Atma Jaya, Yogyakarta, Indonesia \\ suyotodstaff.uajy.ac.id
}

\begin{abstract}
English is important for children because it is an international language that is always used in various fields, both in the world of work, education, economics, and social. One method of learning for children is by playing while learning. Gamification in the field of education is an educational approach to motivate students to enjoy learning by applying the game design. The purpose of this study is to approach the learning of English, specifically for children in kindergarten schools so that children will be more interested and feel happy to continue learning. The gamification method uses a mobile phone-based application with video games. Gamification in question is an English language recognition game for children with games. The introduction of English includes three categories, namely numbers, pictures, and spelling. The result is a mobile-based application that can be used by children to play the introduction of English with the concept of gamification. With gamification, children become more interested and motivated to learn English. Display made it easier to understand and visually appealing. The contribution given through this paper is to motivate children's willingness to learn English through other learning methods, namely gamification. Make children feel comfortable and not afraid to learn new things, especially English.
\end{abstract}

Keywords - Gamification, Mobile Learning, English Learning, Kindergarten

\section{$1 \quad$ Introduction}

Based on data from the Indonesian Ministry of Education and Culture, the number of children in kindergarten is 121,066 people (data.kemdikbud.go.id). The age of kindergarten ranges from 5-6 years, and that age is the ideal age for learning and understanding the environment and basic material. English language education at this time is very important for the future of children because it is needed in various fields, both science and work. Knowledge or provision of knowledge provided must be early. Can be started in everyday life, for example outside of education after the child comes home from school [1]. English is an international language that will be faced in everyday life. However, learning methods in schools are still not able to optimize the ability of children in English. The method that is still commonly used by teachers is still limited to 
giving theories and exercises on a regular basis. This makes the motivation of students to be less in learning English.

Gamification is a new thing that is the adoption of a video game mechanism in other fields. Gamification learning is an educational approach to motivate students to learn by using video game design and playing elements in the learning environment. The goal is to maximize pleasure and involvement by capturing the interests of students and inspiring students to continue learning [2]. Gamification consists of two forms, namely structural without material changes and modified content methods that add subject matter. Gamification is an effective approach in the world of education, even though it has not been fully applied in education in Indonesia. Gamification techniques used in learning design significantly improve understanding and specifically on student enthusiasm [3].

Based on the explanation, the researcher intends to apply the gamification method to motivate children to learn English. The aim of the researchers is that children are increasingly motivated in learning English and helping teachers in giving material. In addition, children will feel happy and comfortable in learning English with the gamification method so that the conception of children who are initially afraid, becomes more confident in learning English [4].

\section{$2 \quad$ Realated Literature}

Based on previous research, increased gamification helped in the learning process among education. Gamification will take over traditional learning methods in the form of scalability, upgrading learning modules [5]. The education system plays an important role in the generation of the nation. Research that has been done is in preschool children aged 5 years, from the first study conducted with the written assessment then assisted with gamification. The results show that language learning, aided by gamification shows a very significant increase.

The development of learning technology is currently growing rapidly. Mobile games at the moment are not just entertainment. For the sector and the purpose of education increasingly motivate the development of educational games. For example, children, especially kindergarten, learn English Language Vocabulary using Augmented Reality. With virtual objects in such a way that 3D users, can interact with their mobile screens [6]. As with this method, children will trigger children to learn with different methods.

Formal learning and no creative way from the teacher will make children feel uncomfortable in learning. Gamification in the field of education is a new method of giving lessons to children that will make children feel comfortable in learning new things. The purpose of the study was to preserve Indonesian culture with an educational game approach. Some related studies have been conducted by researchers before. Kristianti, in a study entitled "Virtual Education with Puzzle Games for Early Childhood: A Study of Indonesia", revealed which is a game for kindergarten education using puzzles. A game that focuses on objects around the environment, which this game uses the Android tab device [7]. 
Similar research related to the development of learning games was carried out by Steinmaurer with the title "sCool - Game-Based Learning in Computer Science Class A Case Study in Secondary Education" is a research that aims to make the course teach some basic programming concepts [8].

Likewise, with research conducted by Guozheng. In a study entitled "Research of Education Game Based on Virtual Reality". This game focuses on educational games discussing educational and game hybrid modes so that it can motivate students, the framework of educational games based on virtual reality [9].

Research on gamification was also carried out by Kusuma et al. Analyzed the gamification model in the world of education with the MDA framework (Mechanics, Dynamics, Aesthetic) [10]. The study produced an analysis that there are several representative gamification models that can be used to increase motivation in learning activities. Mullins, in his paper, explained the success of gamification by giving rise to the emotional feelings of both positive and negative players. The research processes gamification performance with a psychological approach to examine the interactive processes of cognition and emotion [11].

To make an educational game, you must first understand the content and material to be processed. Like research conducted by Rosyid et al. About making serious educational games [12]. The ultimate goal of the research is to facilitate learning and maximize the fun of students in playing seriously.

A variety of forms of learning gamification, one of which is to teach numbers to children and adolescents in a fun way in Brazil. The study was made by Pontes et al. to assist teachers in teaching mathematics to students [13].

Research related to the gamification framework was conducted by Maican et al. in its publication with the topic a study of gamification framework using zero-cost tools. This gamification discusses that is closely related to play and play, that games regardless of gender and age, are considered as tools to relax but also help a person's mental and physical development [14].

Gamification was also developed for children with disabilities. A study with a title "A Gamification Interactive Typing for Primary Visually Impaired Children in Indonesia". This study is gamification to help students with learning to type, which at first the students cannot use computers so that they need applications as a learning process. There are several typing applications for the blind, but it is not yet supported for learning to type, especially in Indonesia [15].

Learning related to the use of mobile will certainly change the habits of students. Research about learning with mobile technologies students' behavior shows that learning to use cellular has indeed increased the growth of cellular technology in our society. In this study, various factors can influence students in using technology for learning. Data was taken from medical students at the University of Coimbra [16].

Based on the literature study conducted, this research focuses on developing English learning models for children with gamification techniques by taking into account the habits and curriculum of education in Indonesia. The purpose of this research is to make children more motivated in learning English. 


\section{Proposed Method}

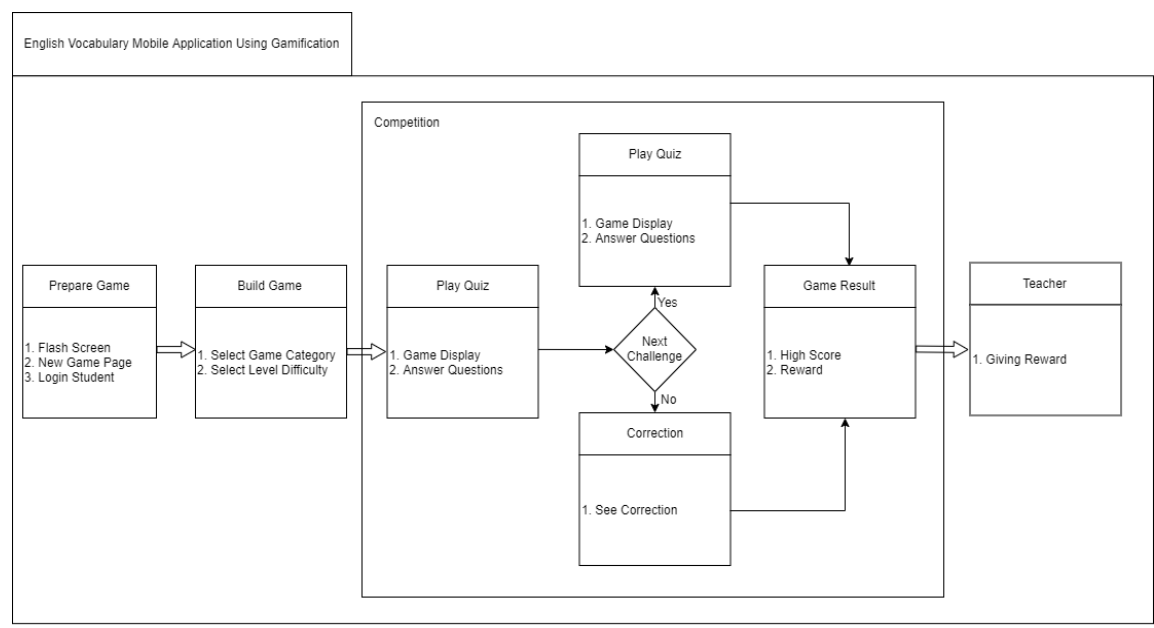

Fig. 1. Proposed Method Flowchart

Figure 1 shows proposed method flowchart, the user first logs into the system then choose the game category you want to play and the level of difficulty. The next step, the user will be faced with a display that contains questions according to the category and level of difficulty chosen. In this step, the user answers the questions given according to the specified time. If all the questions have been answered, then the value will be obtained along with the reward received according to the level of difficulty, and the score received. Result and reward will be recorded and stored in the cloud that can be accessed by the teacher. Users can also see corrections or correct answers when answering questions are wrong. If you want to continue the game, the user can press the next challenge button and choose the desired category and level of difficulty. If you don't want to continue, users can choose the exit menu to exit the game.

If you $\log$ in as a teacher, then the teacher can access the cloud to see the results of the games performed by students. In this way, the teacher can reward children according to the results obtained [17].

In the method that we propose, there are contributions, namely dividing the level of difficulty into three categories, namely easy, medium and difficult. The purpose of dividing the level of difficulty is to adjust the level of learning English with the development of children's thinking. Besides giving rewards to children according to the level of difficulty chosen and the value obtained. Rewards can be in the form of books, pencil boxes, or other items that are suitable for increasing children's motivation in learning English [18]. 


\section{$4 \quad$ Result and Discussion}

\subsection{Quiz education games for kindergarten}

In this game, user divides into two, namely for teachers and students. Display for teachers is different from students.

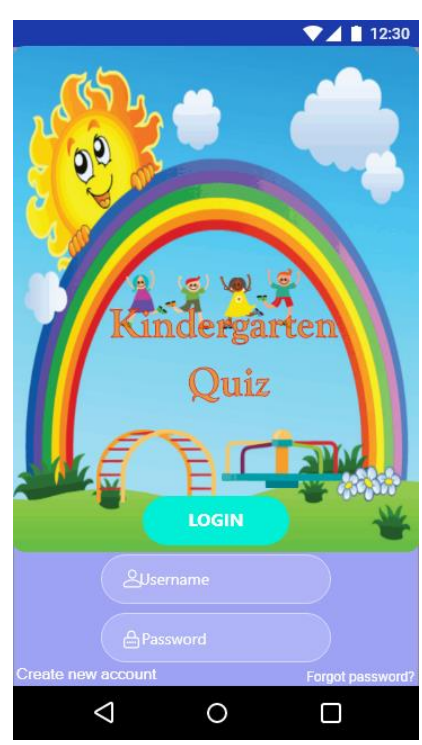

Fig. 2. Initial View

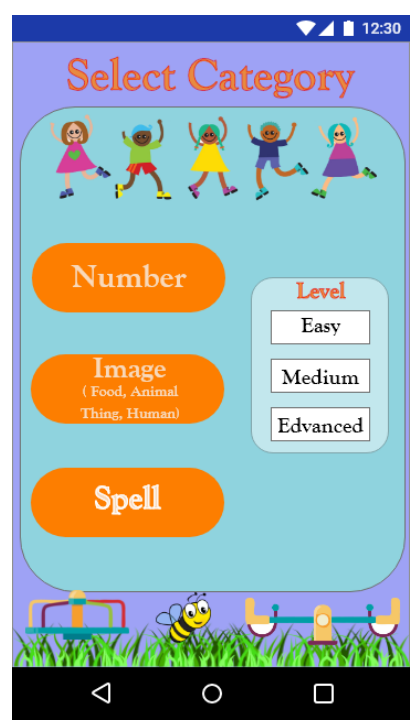

Fig. 3. Categories 


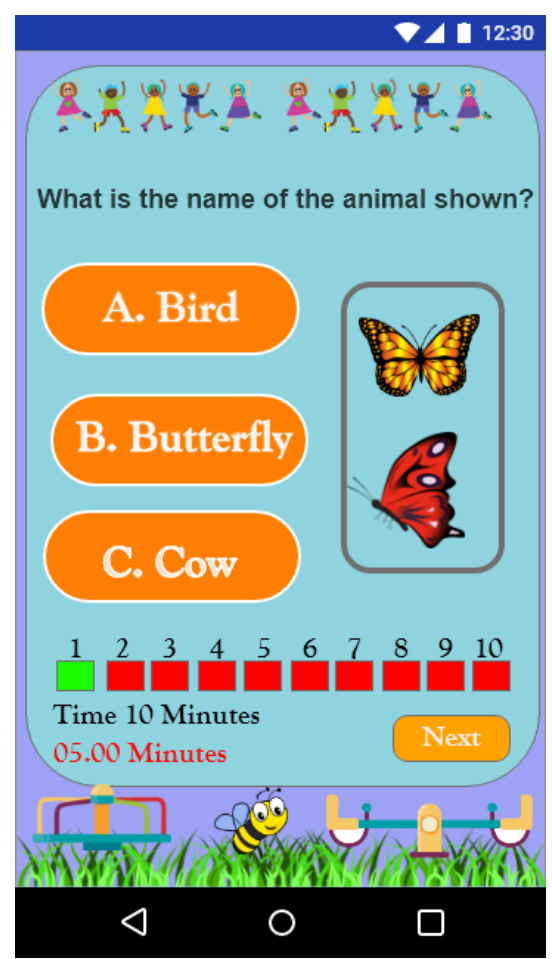

Fig. 4. Quiz Display

In this initial view, student login their username and password, students log in with their respective passwords - likewise, the teacher logs in the username and password.

In figure 3, after logging in, students can choose the game category and level. The games provided are Number, Image, and Spell. These three categories are selected based on the cognitive level of students in the introduction of English and in accordance with the curriculum of kindergarten education. Number, which is a display of questions about numbers, the purpose is to introduce numbers to students. The image consists of foods, animals, things, and human. The purpose of the image category is to introduce objects around it and parts of the human body while the last category is the Spell which contains the spelling of words in English.

The level of difficulty is divided into three (3) categories, which are easy, medium and difficult. The purpose of the level division is to adjust to the level of understanding of students. Students can choose the category and level of difficulty, according to the teacher's direction. After students are able to complete, the teacher can recommend to proceed to the more difficult level.

Figure 4 shows a screen for the image category with the choice of animal(s) at the bottom, and there is a display of questions about 10 with a green that the question has been answered and read that the question has not been answered or has not been done. In the quiz, there are 10 questions that must be completed within 10 minutes. If within 10 minutes has not been completed, the system will lock the answer automatically. 


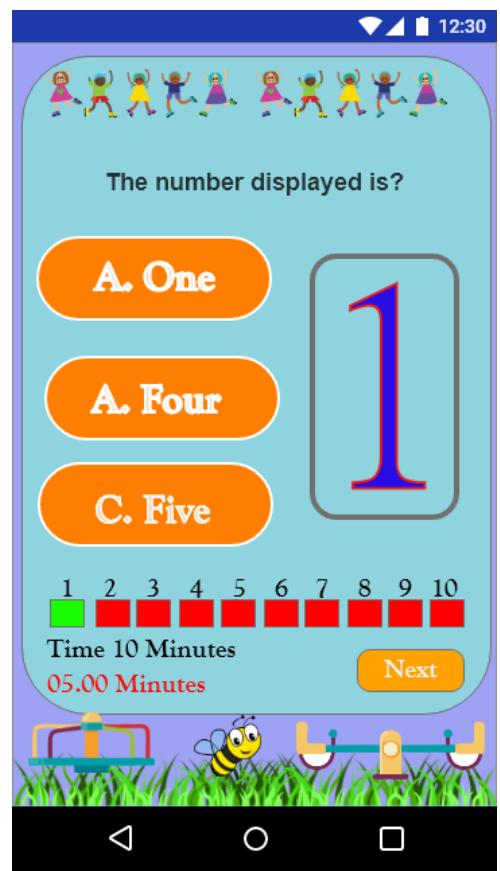

Fig. 5. Easy Level Game

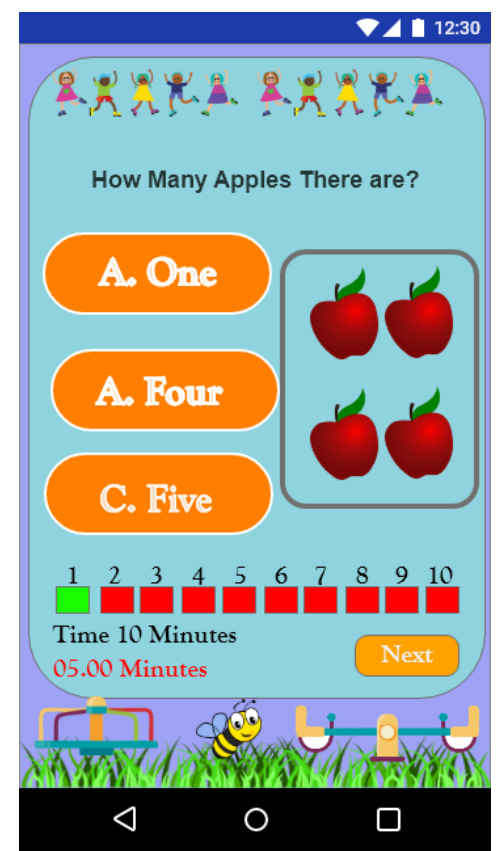

Fig. 6. Medium Level 


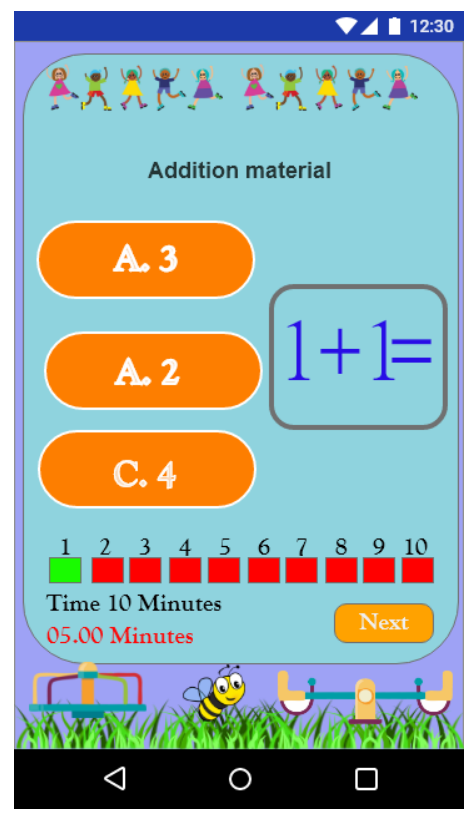

Fig. 7. Advanced Level

Figure 5 is an example of easy game level about numbering. While Figure 6 is an example of a medium level and an advanced 7 level figure. Rewards are given according to the level chosen. On this screen, the system will automatically assess the fastest value and time.

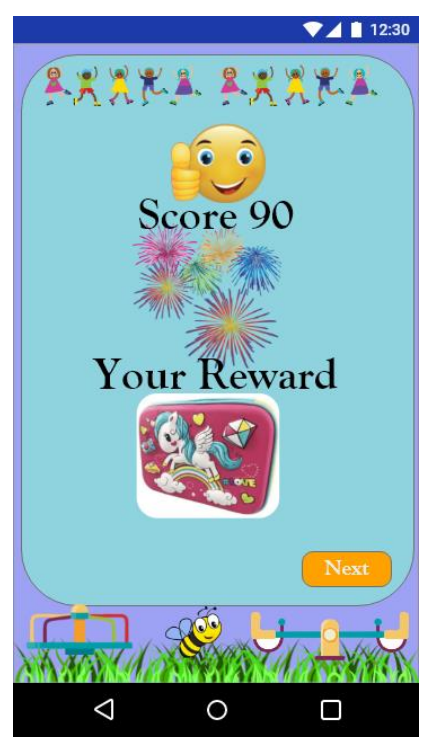

Fig. 8. Reward 


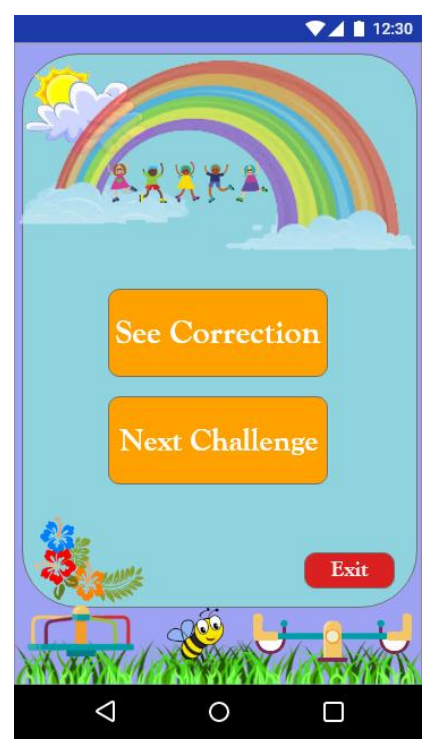

Fig. 9. Choices action

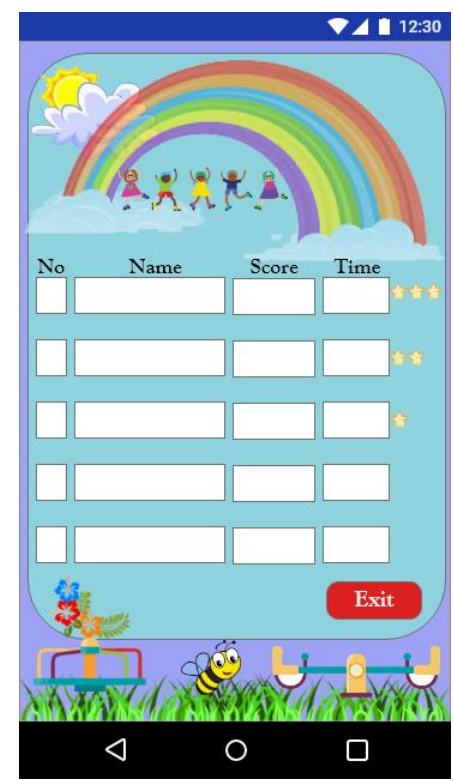

Fig. 10.Scoring

Figure 8 shows that students receive awards according to the chosen point and level. Futhermore, students are faced with 3 choices, namely, to see the correction, continue the game or exit the system (Figure 9). If user press the button to see the correction, the system will display correction in the wrong part of the question. If you press the next 
challenge button, the system will return to the screen, select the category (see Figure 3 ), but if students press the exit button, the system will exit, and the game will end. Figure 10 shows the list of students sorted by ranking. This page can only be accessed by teachers.

Bring up a rewarding display (separated from seeing correction / next challenge), display score and point. This display will appear after the teacher logs into the system (See Figure 2).

For example, in the picture, the child chooses an animal category with a medium difficulty level. When getting a score of 90 , the child gets a reward in the form of a pencil box. The reward is determined based on the level of difficulty and the category chosen by the child. The following table is an example of giving rewards based on level and score.

\subsection{Scoring and reward list}

Table 1. Tabel Scores and rewards

\begin{tabular}{|l|l|c|l|}
\hline \multicolumn{1}{|c|}{ Category } & \multicolumn{1}{c|}{ Level } & Score & \multicolumn{1}{c|}{ Reward } \\
\hline Image-Animal & Easy & 70 & 2 pencils \\
\hline Image-Animal & Easy & 80 & Pencil case \\
\hline Image-Animal & Easy & 90 & Pencil case +1 pencil \\
\hline Image-Animal & Easy & 100 & Pencil case +1 pencil + 1 eraser \\
\hline Image-Animal & Medium & 70 & 2 pencils +1 eraser \\
\hline Image-Animal & Medium & 80 & Pencil case +1 pencil +1 eraser \\
\hline Image-Animal & Medium & 90 & Pencil case +2 pencil +1 eraser \\
\hline Image-Animal & Medium & 100 & Pencil case +1 pencil +1 eraser +1 note book \\
\hline Image-Animal & Advanced & 70 & Drinking bottle + pencil case +1 pencil \\
\hline Image-Animal & Advanced & 80 & Lunch box + pencil case +1 pencil \\
\hline Image-Animal & Advanced & 90 & School shoes \\
\hline Image-Animal & Advanced & 100 & School shoes +1 socks \\
\hline
\end{tabular}

Table 1 shows the distribution of rewards is divided into 3 categories of levels, which are easy, medium and advanced. The highest order value is 100 , and the lowest is 70 . Based on discussions with kindergarten teachers, the rewards given are adjusted to the needs of students for school needs. Rewards are given according to the level reached by students. Assessment is based on many questions that are answered correctly and according to the level of choice. Each question has a value of 10. The form of reward is chosen because the target users are kindergarten students so that children will feel active to learn more. The form of reward given is adjusted to the level chosen. The higher the level chosen, the more rewards. These items include pencils, erasers, drinking water containers, socks, and shoes. Each of these rewards has animations or colors as illustrated by favorite cartoon characters (hello, little pony, frozen, Tom \& Jerry, Batman, Power Rangers, Superman), colors, and so on.

Children are often addicted to playing mobile games, so to avoid this, this game will only be used with teacher supervision and is done in the classroom. 


\section{Conclusion}

Kindergarten is the process of children to learn quickly and great curiosity. Children also have psychographic characteristics such as high activity levels and high curiosity. They love to see something new and high in creativity. Observation of English learning gamification is done by interviewing children randomly. Based on observations made in kindergarten, the most preferred category is number (number) and Image (image) because it has an attraction in terms of appearance. This attraction will stimulate the child's desire to continue learning.

In the development of educational games, there are several things that must be considered, namely: clear game instructions, challenging learning environments, game control options, and attractive game appearance. A visually interesting game must have a background design, animation, and sound that sounds good.

Providing attractive rewards and in accordance with the character of the child, will increasingly trigger to want to continue learning. The factors that trigger children in learning English are the desire to get the highest reward and achieve the highest score. With the presence of levels in this educational game, it will also make children more motivated to level up and feel themselves getting smarter.

Attractive appearance and questions adapted to the learning curriculum make children become increasingly interested in learning English. Subsequent development in animation and a bright appearance so as to attract the interest of children in learning.

\section{References}

[1] D. L. Linklater, R. E. O'Connor, and G. J. Palardy, "Kindergarten literacy assessment of English Only and English language learner students: An examination of the predictive validity of three phonemic awareness measures," J. Sch. Psychol., vol. 47, no. 6, pp. 369394, 2009. https://doi.org/10.1016/j.jsp.2009.08.001

[2] A. Uskov and B. Sekar, "Smart Gamification and Smart Serious Games," in Intelligent Systems Reference Library, 84th ed., D. Sharma, M. Favorskaya, L. C. Jain, and R. J. Howlett, Eds. London: Springer Berlin Heidelberg, 2015, pp. 7-36. https://doi.org/10.10 07/978-3-319-14645-4_2

[3] D. Kayimbaşioğlu, B. Oktekin, and H. Haci, "Integration of Gamification Technology in Education,” Procedia Comput. Sci., vol. 102, no. August, pp. 668-676, 2016. https://doi. org/10.1016/j.procs.2016.09.460

[4] S. Mader and F. Bry, "Fun and Engagement in Lecture Halls through Social Gamifica tion,”. Int. J. Eng. Pedagog., vol. 9, no. 2, p. 117, 2019. https://doi.org/10.3991/ijep.v9i2. $\underline{10163}$

[5] S. Hong and E. Kim, Development of Gesture Recognition Education Game for Elementa ry School Students Personality Education, vol. 850. Springer International Publishing, 2018.

[6] L. K. Lee, C. H. Chau, C. H. Chau, and C. T. Ng, "Using augmented reality to teach kindergarten students english vocabulary," Proc. - 2017 Int. Symp. Educ. Technol. ISET, 2017, pp. 53-57, 2017. https://doi.org/10.1109/iset.2017.20

[7] N. Kristianti, S. Niwayan Purnawati, and Suyoto, "Virtual education with puzzle games for early childhood: A study of Indonesia," Int. J. Eng. Pedagog., vol. 8, no. 2, pp. 14-22, 2018. https://doi.org/10.3991/ijep.v8i2.7943 
[8] A. Steinmaurer, J. Pirker, and C. Gütl, "sCool - Game-Based Learning in Computer Science Class: A Case Study in Secondary Education," Int. J. Eng. Pedagog., vol. 9, no. 2, p. 35, 2019. https://doi.org/10.3991/ijep.v9i2.9942

[9] W. Guozheng and W. Haiyan, "Research of education game based on virtual reality," Proc. - 2008 Pacific-Asia Work. Comput. Intell. Ind. Appl. PACIIA, 2008, vol. 2, pp. 921-924, 2008.

[10] G. P. Kusuma, E. K. Wigati, Y. Utomo, and L. K. Putera Suryapranata, "Analysis of Gamification Models in Education Using MDA Framework," Procedia Comput. Sci., vol. 135, pp. 385-392, 2018. https://doi.org/10.1016/j.procs.2018.08.187

[11] K. Mullins and R. Sabherwal, "Gamification: A cognitive-emotional view," J. Bus. Res., no. September 2018.

[12] H. A. Rosyid, M. Palmerlee, and K. Chen, "Deploying learning materials to game content for serious education game development: A case study," Entertain. Comput., vol. 26, no. March 2017, pp. 1-9, 2018. https://doi.org/10.1016/j.entcom.2018.01.001

[13] H. P. Pontes, J. B. Furlan Duarte, and P. R. Pinheiro, "An educational game to teach numbers in Brazilian Sign Language while having fun," Comput. Human Behav., 2018. https://doi.org/10.1016/j.chb.2018.12.003

[14] C. Maican, R. Lixandroiu, and C. Constantin, "Interactivia.ro - A study of a gamification framework using zero-cost tools," Comput. Human Behav., vol. 61, pp. 186-197, 2016. https://doi.org/10.1016/j.chb.2016.03.023

[15] Yanfi, Y. Udjaja and A. C. Sari, "A Gamification Interactive Typing for Primary School Visually Impaired Children in Indonesia," Procedia Comput. Sci., vol. 116, pp. 638-644, 2017. https://doi.org/10.1016/j.procs.2017.10.032

[16] L. Briz-Ponce, A. Pereira, L. Carvalho, J. A. Juanes-Méndez, and F. J. García-Peñalvo, "Learning with mobile technologies - Students' behavior," Comput. Human Behav., vol. 72, pp. 612-620, 2017. https://doi.org/10.1016/j.chb.2016.05.027

[17] S. Hakak et al., "Cloud-assisted gamification for education and learning - Recent advances and challenges," Comput. Electr. Eng., vol. 74, pp. 22-34, 2019.

[18] J. Hwang and L. Choi, "Having fun while receiving rewards?: Exploration of gamification in loyalty programs for consumer loyalty," J. Bus. Res., no. January, pp. 1-12, 2019. https://doi.org/10.1016/j.jbusres.2019.01.031

\section{Authors}

Gabriel Indra Widi Tamtama is a Master Student in the Department of Informatics Engineering at Universitas Atma Jaya Yogyakarta, Yogyakarta, Indonesia. Majoring in computer systems and data communication. He received his Bachelor's Degree at Sanata Dharma University Yogyakarta. His research interests are mobile applications, deep learning, artificial intelligence and user interface design.

Paulus Suryanto is a Master Student in the Department of Informatics Engineering at Universitas Atma Jaya Yogyakarta, Yogyakarta, Indonesia. Majoring in computer systems and data communication. He received his Bachelor Degree at STMIK AKAKOM Yogyakarta. His research interests are mobile applications, artificial intelligence and user interface design.

Suyoto is Professor in the Department of Informatics Engineering at Universitas Atma Jaya Yogyakarta, Indonesia. He has more than nineteen years of teaching expe- 
rience. He received his $\mathrm{PhD}$ in 2000 from the National University of Malaysia, Malaysia. His research interests are multimedia, computer graphics, visualisation, mobile application and artificial intelligence.

Article submitted 2019-08-20. Resubmitted 2019-10-14. Final acceptance 2019-10-17. Final version published as submitted by the authors. 